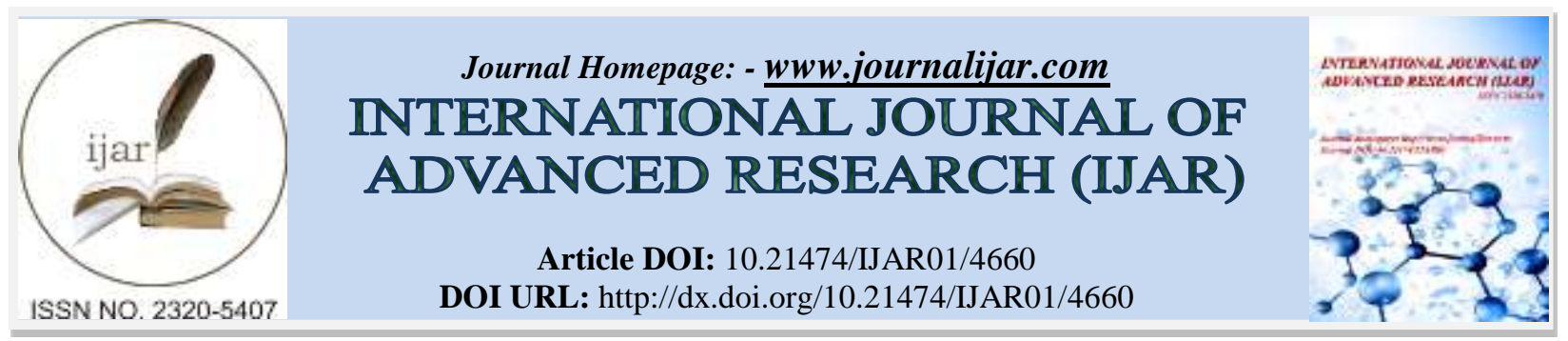

RESEARCH ARTICLE

\title{
EARLY CHILDHOOD CARE AND EDUCATION FOR CHILDREN WITH SPECIAL NEEDS: A WAY TO SUCCESSFUL INCLUSION.
}

\author{
*Ratan Sarkar. \\ Senior Research Fellow (Ph.D. in Education), School of Education, Pondicherry University (A Central University), \\ Kalapet, Puducherry-605014, India.
}

\section{Manuscript Info}

(........................

Manuscript History

Received: 24 April 2017

Final Accepted: 29 May 2017

Published: June 2017

Key words:-

Children with Special Needs;

Anganwadi; Early Childhood Care and

Education; Successful Inclusive

Education.

\section{Abstract}

Inclusive education is the most feasible plan of getting across of education to each child. When a country talks about education, it is "Education for All", without leaving anyone. The fundamental principle of inclusive school is that all children should learn together wherever possible regardless of any difficulties or differences they may have. When the trend of inclusion prevailing not only across the country but also all over the world, in that condition how the Anganwadi centers which provide pre-primary education, meaning thereby to make the child ready for the elementary education in inclusive set up, be untouched with this trend of inclusion. With the emergence of "Inclusion" Anganwadi is also supposed to deal with the children with special needs. Anganwadi centres might be envisaged as the best preparatory centre for the holistic development of children which uses play way method of teaching with indigenous approach. It is contributing towards preparing the child for elementary school. And at last, it is a move towards universalization and qualitative improvement of primary education. The relevance of the present paper lies in the fact that Anganwadi centre which covers a large area across the country should meet the needs of children considering their different rates and styles of learning in uniform manner. The present paper intends to bring forth the role of ECCE provided through Anganwadi centres and measures to be taken to equip Anganwadi centres to include children with special needs into mainstream.

Copy Right, IJAR, 2017,. All rights reserved.

"The success of the inclusive school depends considerably on early intervention, assessment and stimulation of the very young child with special educational needs. Early childhood care and education programmes for children aged up to six years ought to be developed and/or reoriented to promote physical, intellectual and social development and school readiness... Programmes at this level should recognize the principle of inclusion and be developed in a comprehensive way by combining pre-school activities and early childhood health care."

\section{-- Salamanca Framework for Action (1994), Article-53}

'The children of today are the future of tomorrow'; with this powerful statement comes the responsibility to mould and shape our children in order to create the best possible future for everyone. Making of a nation depends largely

\section{Corresponding Author:- Ratan Sarkar.}

Address:- Senior Research Fellow (Ph.D. in Education), School of Education, Pondicherry University (A 
upon the sound development of children. Hence, for formation of civilized, cultured, and peaceful and healthy society, any country needs to educate and train its children properly. The appropriate care children receive while they are young or the manner, in which their needs are met, has a remarkable impact on their intelligence, personality, and social interaction well into adulthood. India has been striving hard to make 'Education For All' successful. For the said purpose, it has launched many policies, programmes, schemes, legislations and so on. And eventually it made education a fundamental right with introduction of Right of Children to Free and Compulsory Education Act (2009). One the one hand Right to Education Act has brought education under fundamental right of every child between ages 6 to 14 years to get elementary education; it neglects a large chunk of population who is below six years on the other. As the Act defines child as "a male or female child of the age of six to fourteen years" clearly shows how it deprives the rights to education for those who are below 6 years. However, research studies clearly indicate that early years are very crucial for maximum development of brain of children. The findings of these research studies lay tremendous emphasis on the early years of pre-primary education.

The Government of India proclaimed National Policy on Child in August 1974 declaring children as 'supremely important assets'. The policy provided the required framework for assigning priority to different needs of the child. The erstwhile Ministry of Education and Social Welfare launched a national programme in all districts of the country known as the Integrated Child Development Services (ICDS) on $2^{\text {nd }}$ October, 1975. The ICDS with its network of Anganwadis covering entire country is perhaps the largest child development programme being implemented anywhere in India. The advantage of this system is that it would be possible to respond optimally to specific features of the local environment or to the local demands (Seema, 2001). It provides Early Childhood Care and Education (ECCE, henceforth) which assumes importance for ensuring holistic development of very child. ECCE might be regarded as a significant input for providing a sound foundation for child's development and the preparatory ground for schooling in the later years. Presently dropout rate at elementary level in India is approximately $40 \%$ which is very high. Negligence of proper provision of ECCE or Pre-primary education is one of the major reasons of the high dropout rate in India whereas ECCE has tremendous impact on the success at elementary level. Anganwadi centres are usually providing ECCE to non-disabled children in India. However, when it comes to CWSN, the situation is more alarming. For their early intervention, which is very essential for success at later years, there is no scheme at national level except in few cities.

Education of CWSN has never received such amount of consideration and special efforts by government agencies in the past as in the present days. Now inclusive education is the most feasible plan of getting across of education to each child. When a country talks about education, it is "Education for All", without leaving anyone. The fundamental principle of inclusive school is that all children should learn together wherever possible regardless of any difficulties or differences they may have. When the trend of inclusion prevailing not only across the country but also all over the world, in that condition how the Anganwadi centres which provide pre-primary education, meaning thereby to make the child ready for the elementary education in inclusive set up, be untouched with this trend of inclusion. The present paper intends to highlight the (i) need of ECCE for CWSN, (ii) role of ECCE provided through Anganwadi centres towards success of CWSN in mainstream education, (iii) existing challenges of ECCE for CWSN in India, and (iv) measures to be taken to equip Anganwadi centres to include CWSN into mainstream.

\section{Need of Early Childhood Care and Education for CWSN:-}

The population of individuals with special needs in the world is about 650 million and this accounts for $10 \%$ of global population and constitutes $20 \%$ of the world's poorest people. Children with special needs are often stigmatized from birth and more vulnerable to exclusion, concealment, abandonment, institutionalization and abuse (Thomas, 2005). Mortality rates among CWSN are 80\% even in countries where under-five mortality has declined below 20\%. Most importantly, 98\% of CWSN, in developing countries including India, do not attend school (UNESCO, 2009). United Nations Conventions on the Rights of Persons with Disabilities (UNCRPD), which was ratified by India on $1^{\text {st }}$ October, 2007, was one of the remarkable strides towards recognizing individuals with special needs as equal and active members of the society. The UNCRPD promises to safeguard all human rights and fundamental freedoms of children and adult with special needs, and highlights the need of early intervention and inclusion in the education system from an early age. It also argues that ECCE is a powerful means of nurturing diverse abilities, overcoming disadvantages and inequalities and calls for responding to developmental needs of every child with special needs.

Research reveals that $80 \%$ of the brain's capacity develops before the age of three years and thus the early ECCE offer a special opportunity to foster developmental gains in children. It is also found that these gains are highest for 
those with maximum disadvantages. Equivalently negligence in early ECCE can lead to long lasting disabling effects. Poor nutrition leads to early childhood stunting, and coupled with low stimulation, it contributes to the poor cognitive and educational performance of children (Grantham-McGregor et al., 2007). An inclusive and enabling ECCE programme enhances the effects of interventions for CWSN. Favorable transition from home to preschool is encouraged on the conditions that the ECCE programme is equipped with child centred pedagogy and necessary individualized support capable to meet the diverse needs of CWSN with different styles and rates of learning (ISSA, 2006). Thus, it is evident that a responsive and competent ECCE programme benefits all children including CWSN and contributes to promote readiness of children for mainstream education at primary level and above and this eventually helps in building the foundations of an inclusive society.

Role of ECCE Provided through Anganwadi Centres towards Success of CWSN in Mainstream Education:Early childhood care and education provided through Anganwadi centres has an imperative role towards preparing CWSN for successful inclusion and highest gain in the mainstream education system. It is well accepted fact that 'prevention is better than cure'. Early childhood care and education help to identify and support the children 'at risk'. Through early assessment coupled with intervention, one can gain relevant information, especially about what child can do and about interventions that will optimize his/her learning potential. This also increases the chances that CWSN can participate and flourish in inclusive mainstream educational settings. Research reveals that one in three infants and toddlers who receive early intervention services do not experience disability in future or require special education in a preschool (Hebbeler et al., 2003). Additionally, experts also argue that investments in early ECCE are wiser than those made at any other age.

Early childhood care and education provided through Anganwadi Centres has the aim to develop in the children including CWSN- (i) good physique, muscular coordination, basic motor skills; (ii) stimulating intellectual curiosity to enable child to understand his/her environment by exploring, investing, experimenting and learning; (iii) aesthetic appreciation of self, others, things and environment; (iv) emotional maturity by guiding to express, understand, accept and control feelings and emotions; (v) moral and cultural values so as to be honest, obedient, sincere, compassionate, truthful and respectful to elders; (vi) self-confidence and inner discipline; (vii) ability to express thoughts and feelings in fluent, correct and clear language; (vii) personality through rich learning experience; (viii) social attitude, group manners and sharing things with others, live \& play with others and control natural aggressiveness and destructiveness; and (ix) good conducts, skills for personal adjustment and ability to perform activities of daily living independently etc. Adding to that, all these are very imperative to promote all round development of a child and ensure his/ her gainful and complete participation in the regular education set up at primary level or above.

\section{Existing Challenges of ECCE for CWSN in India:-}

It is imperative to know about the existing challenges in order to bring radical change in any situation. The main challenges for promoting early childhood care and education for children with special needs through anganwadi centres in India to facilitate their comprehensive and productive inclusion in the mainstream primary education are highlighted below.

- Defective educational policy.

- Unserved habilitation and areas.

- Lack of trained Anganwadi worker.

- Inadequate infrastructure and resource required.

- Poor quality monitoring of Anganwadi workers.

- Service delivery not focused on children under three.

- No standard curriculum and nationalized curriculum.

- Ineffective training programme for Anganwadi workers.

- Poor maintenance of growth charts for the child beneficiaries.

- Corrupt practices prevail in recruitment of Anganwadi workers.

- Dilution of focus on the children with severe or profound disabilities.

- Too much emphasis on food security and not on pre-school education.

- Level of awareness among the intended beneficiaries about their entitlement.

- The system of record maintenance in most of the Anganwadi Centres is poor.

- Lack of initiatives to enable Anganwadi workers to meet the needs of CWSN.

- Anganwadi workers are overburdened, underpaid, ignorant and mostly unskilled. 
- Lack of fund to render specialized services as required by different types of CWSN.

- Exclusion from ICDS benefits on the basis of caste has been observed in some cases.

- Convergence of complementary services, which is essential for realization of ECCE goals, is a weak link.

- No legal instruments for the provision of necessary infrastructure and for professional support to ICDS.

- The administration and supervision of the works assigned to the Anganwadi centres are found to be very weak.

- Negligence of duty of part of the Anganwadi workers and the supervisor has further contributed to this failure.

- Anganwadi centre is dysfunctional due to corruption of the Anganwadi workers and the callousness of the supervisors and other senior officials.

- Lack of collaboration between school and Anganwadi workers and other support service centres like therapy centres, early interventions \& assessment centres, rehabilitation centre, primary health centres etc.

- The poorest states (northern states) with high levels of child malnutrition and nearly half of India's population have the lowest programme coverage and the lowest budgetary allocations from the central government.

- The quality of food is extremely low; vaccination and health care facilities are nonexistent due to high costs of vaccines, play kits are not there in pre-school etc. Lack of funds seems to be a major problem in this Anganwadi centres.

Measures to be taken to Equip Anganwadi Centres to Include CWSN into Mainstream:-

To address the above discussed challenges and to equip the Anganwadi centres to include children with special needs into mainstream education the following measures can be suggested.

- The role of Anganwadi workers must be well recognized.

- Anganwadi workers should be given vocational training.

- Linkage between anganwadi and schools needs to be ensured.

- Separate budget allocation must be provided to Anganwadi centres for CWSN or children 'at risk' under ICDS from the Government pool.

- Basic amenities must be made available at the each Anganwadi centre all over the country. Additionally, more number of learning/play materials to be provided to Anganwadi centres for CWSN and its maintenance/ repairing to be done periodically.

- Separate Anganwadi workers for 0-3 years and 3-6 years children may be appointed.

- Proper coordination should be maintained between the supervisors, Anganwadi workers, CDPO, community and Anganwadi centre. This can be made possible only through regular meetings and collaboration between them or a village management committee.

- Sound educational policy of pre-school education for CWSN should be framed and enforced by the government with clear execution plan and obligatory roles to be performed by various stakeholders.

- Initiative must be taken for giving proper training to Anganwadi workers and families with CWSN on educational, developmental and other needs of CWSN.

- Uniform, standard and nationalized framework for curriculum having link with regional culture, traditions, beliefs, and mainstream schooling curriculum should be formed for the ECCE programme of CWSN.

- Anganwadi centres may issue a certificate to all the children on completion of preschool education, which will be an authentication to get into mainstream schools.

- Controls need to be brought into place to curb the rampant corruption. Senior officials need to step in with regular checks.

- A language barrier exists in pre-school education. Therefore, the Anganwadi workers should be chosen and trained to communicate and teach in the local language.

- Concerned department of govt. of India should suggest a framework for regulatory work on the curriculum. Additionally, the mal-functions of the system because of distorted priorities may also be highlighted and brought into the notice of the concerned departments without any delay.

- A pragmatic policy measures must to be taken to ensure investment in early assessment \& intervention, universalizing access to early childhood inclusive education and community based educational provision with reliable specialist support.

- The location of Anganwadi centre is a major factor behind the good functioning of the Anganwadi centre. The Anganwadi centre should be centrally located and easily accessible. Location of a dispensary with adequate and available infrastructure to regulate health and growth of all CWSN can play a vital role towards success of Anganwadi centres. 
- Awareness training should be conducted for families, officials and local leaders which would ensure the proper management and quality of ECCE service through their cooperation and participation. For ECCE to deliver its benefits to CWSN and to 'be effective, accessible and equitable, a society must invest in it'.

- Food is a major attraction of the poor people in the community. Hence the food supply mechanism should be smooth in all the Anganwadi centres. Further, for the supply mechanism to be smooth, allocation of funds plays a very important role. Funds for food items should be regularly revised, keeping in mind the food inflation.

- The salary structure and incentive of promotion of the Anganwadi workers to the supervisors rank play a very important role in their proper functioning. Therefore, proper strategy should be followed in this regard without any bias and political interference to ensure reasonable salary and promotion of the Anganwadi workers.

- The Anganwadi workers should get refresher training periodically on current trends, developments and practices of inclusive education at pre-school level for CWSN.

- Regular feedbacks should be taken from the families of the beneficiaries about the quality of ECCE provided through Anganwadi centres.

\section{Conclusion:-}

In India, according to Census 2011 data, there are 164.48 million children of 0-6 years of age.

Children are born ready to learn. They cultivate 85 percent of their intellect, personality and skills by age five. The first 0-6 years of life set the stage for lifelong development. The early brain development has serious positive impact on later life of individuals, especially for children with disabilities or 'at risk'. Recognizing this fact, the need to provide quality preprimary programmes was felt and a number of constitutional and policy provisions have been made such as the 86th Constitutional Amendment which introduced Article 21 A on the right to free and compulsory education for 6-14 years old children and Article 45 to urge states to provide ECCE for all children including CWSN until they complete the age of six years. Although, the Right of Children to Free and Compulsory Education (RTE) Act 2009 guarantees children their right to quality elementary education. ECCE is not recognized as a compulsory provision by RTE, but RTE urges states to provide free preschool education for children above 3 years leaving children below 3 years on margins. The $12^{\text {th }}$ Five Year Plan acknowledges the importance of ECCE and improving school preparedness. The Government of India approved the National Early Childhood Care and Education (ECCE) Policy in 2013 but the Policy framework does not talk much about the systematic strategies to be adopted for addressing the specific needs of CWSN while including the National Curriculum Framework and Quality Standards for ECCE. This is undoubtedly a negative sing towards improvement of ECCE programme for CWSN in the country. However, with the emergence of 'Inclusion' Anganwadi is also supposed to deal with the CWSN. Anganwadi centres might be envisaged as the best preparatory centre for the holistic development of children which uses play way method of teaching with indigenous approach. It is contributing towards preparing the child for mainstream schooling. Furthermore, it is a move towards universalization and qualitative improvement of primary education. The significance of the present paper lies in the fact that Anganwadi centre which covers a large area across the country can be a viable way to meet the needs of all children including children with special needs considering their different rates and styles of learning in a uniform manner. Thus, it can be concluded that if Anganwadi centres are equipped well and Anganwadi workers are trained properly to deal with CWSN, they can positively contribute to make "Inclusion Successful".

\section{References:-}

1. Grantham-McGregor, S., Bun Cheung, Y., Cueto, S., Glewwe, P., Richter, L., \& Strupp, B. (2007). Developmental potential in the first 5 years for children in developing countries. Lancet, 369(9555), 60-70.

2. Hebbeler, K., Spiker, D., Mallik, S., Scarborough, A., \& Simeonsson, R. (2003). The National Early Intervention Longitudinal Study. Demographic characteristics of children and families entering early intervention. NEILS Data Report 3. Menlo Park, CA: SRI International.

3. ISSA. (2006). Documenting Educational Reform: the Step by Step Case Study project. New York: Open Society Institute \& Soros Foundations Network.

4. Penn, H. (2004). Childcare and early childhood development programmes and policies: their relationship to eradicating child poverty. CHIP Report 8, CHIP, London: Childhood Poverty Research and Policy Centre.

5. Seema, T. N. (2001). Performance of Anganwadi centres in Kerala: An evaluation and experiment to develop a model centre with community participation. Discussion paper no. 28, 2001. Kerala Research Programme on Local Level Development, Centre for Developmental Studies, Thiruvanthapuram, Kerala, India.

6. Thomas, P. (2005). Disability, Poverty and the MDGs. United Kingdom: The Department for International Development (DFID). 
7. UNESCO. (2009). Inclusion of children with disabilities: The early childhood imperative. UNESCO policy brief on early childhood, no. 46, April- June, 2009. Paris: UNESCO

8. World Vision Armenia focus group discussions with teachers, specialists and parents, February, 2009.

9. http://indiatoday.intoday.in/story/india-has-40-per-cent-drop-out-rate-in-elementary-schools/1/324717.html. 